\title{
Cancellations of (helicopter-transported) mobile medical team dispatches in the Netherlands
}

\author{
Georgios F. Giannakopoulos - Wouter D. Lubbers • Herman M. T. Christiaans • \\ Pieternel van Exter • Piet Bet • Paul J. C. Hugen • Gerard Innemee • Edo Schubert • \\ Elly S. M. de Lange-Klerk • J. Carel Goslings $\cdot$ Gerrolt N. Jukema
}

Received: 14 September 2009 / Accepted: 9 November 2009 /Published online: 19 January 2010

(C) The Author(s) 2009. This article is published with open access at Springerlink.com

\begin{abstract}
Background The trauma centre of the Trauma Center Region North-West Netherlands (TRNWN) has consensus criteria for Mobile Medical Team (MMT) scene dispatch. The MMT can be dispatched by the EMS-dispatch centre or by the on-scene ambulance crew and is transported by helicopter or ground transport. Although much attention has been paid to improve the dispatch criteria, the MMT is often cancelled after being dispatched. The aim of this study was to assess the cancellation rate and the noncompliant dispatches of our MMT and to identify factors associated with this form of primary overtriage.

Methods By retrospective analysis of all MMT dispatches in the period from 1 July 2006 till 31 December 2006 using chart review, we conducted a consecutive case review of 605 dispatches. Four hundred and sixty seven of these were
\end{abstract}

G. F. Giannakopoulos $(\bowtie) \cdot$ W. D. Lubbers $\cdot$ G. N. Jukema

Department of Trauma Surgery,

VU University Medical Centre,

7F-018, P.O. Box 7057,

1007 MB Amsterdam, The Netherlands

e-mail: gf.giannakopoulos@vumc.nl

\section{H. M. T. Christiaans}

Department of Anesthesiology,

VU University Medical Centre,

Amsterdam, The Netherlands

P. van Exter

Regional Medical Manager of Ambulance Services (MMA),

Region Amsterdam, The Netherlands

P. Bet

Regional Medical Manager of Ambulance Services (MMA),

Region Noord-Holland Noord, The Netherlands included for our study, collecting data related to prehospital triage, patient's condition on-scene and hospital course. Results Average age was 35.9 years; the majority of the patients were male $(65.3 \%)$. Four hundred and thirty patients were victims of trauma, sustaining injuries in most cases from blunt trauma (89.3\%). After being dispatched, the MMT was cancelled 203 times (43.5\%). Statistically significant differences between assists and cancellations were found for overall mortality, mean RTS, GCS and ISS, mean hospitalization, length and amount of ICU admissions $(p<0.001)$. All dispatches were evaluated by using the MMT-dispatch criteria and mission appropriateness criteria. Almost $26 \%$ of all dispatches were neither appropriate, nor met the dispatch criteria. Fourteen missions were appropriate, but did not meet the dispatch criteria. The remaining 318 dispatches had met the dispatch criteria, of which 135

\section{P. J. C. Hugen}

Regional Medical Manager of Ambulance Services (MMA),

Region Kennemerland, The Netherlands

G. Innemee

Regional Medical Manager of Ambulance Services (MMA),

Region Gooi \& Vechtstreek, The Netherlands

E. Schubert

Regional Medical Manager of Ambulance Services (MMA),

Region Flevoland, The Netherlands

E. S. M. de Lange-Klerk

Department of Epidemiology and Biostatistics,

VU University Medical Centre,

Amsterdam, The Netherlands

J. C. Goslings

Trauma Unit, Department of Surgery, Academic Medical Center, Amsterdam, The Netherlands 
$(30.3 \%)$ were also appropriate. The calculated additional costs of the cancelled dispatches summed up to a total of $€ 34,448$, amounting to $2.2 \%$ of the total MMT costs during the study period.

Conclusion In our trauma system, the MMT dispatches are involved with high rates of overtriage. After being dispatched, the MMT is cancelled in almost $50 \%$ of all cases. We found an undertriage rate of $4 \%$, which we think is acceptable. All cancellations were justified. The additional costs of the cancelled missions were within an acceptable range. According to this study, it seems to be possible to reduce the overtriage rate of the MMT dispatches, without increasing the undertriage rate to nonacceptable levels.

Keywords HEMS · Overtriage · Dispatch criteria · Trauma

\section{Introduction}

Trauma triage systems seek to identify and provide rapid treatment for the most severely injured trauma patients while at the same time identifying less-injured patients in need of only basic care. These systems have been shown to substantially reduce injury-related morbidity and mortality [1-3]. An ideal system would equally match the severity of injury and resources required for optimal care with the appropriate trauma facility and personnel. However, in practice, it is shown that a "perfect" triage system is not possible, resulting in ruling out overtriage and undertriage. As stated in the American College of Surgeons Committee on Trauma guidelines, “... in general, priority has been given to decrease of undertriage, because undertriage may result in preventable mortality or morbidity from delays in definitive care" [4].

Undertriage may lead to delayed diagnostics and inefficient resuscitative measures. Overtriage means in- creased workload at the receiving trauma centre and the inefficient use of healthcare resources. Overtriage may also cause longer out-of-hospital transport times and loss of emergency medical service coverage in the primary area [5], although it is necessary to some extent in order to reduce preventable deaths. Even though decrease of undertriage should result in fewer missed injuries or delays in receiving definitive care, the inevitable result has been an increase in overtriage of patients with less-severe or negligible injuries.

In 1995, helicopter-transported mobile medical teams (H-MMTs) were introduced in the Netherlands. The first H-MMT was based on the VU Medical Center in Amsterdam, a level-I trauma centre of the Trauma Center Region North-West Netherlands (TRNWN). The aim of this concept was the delivery of a trauma team to the scene of the accident as quickly as possible, in addition to the ambulance crew. The mobile medical teams consist of a specially trained physician (a trauma surgeon or an anesthesiologist) and an Emergency Room (ER)/Emergency Medical Services (EMS) nurse. They add advanced airway management, rapid sequence intubation, placement of chest tubes, administration of specific medication and limited surgical interventions to the on-scene therapeutic spectrum.

During daylight hours, almost $80 \%$ of the Dutch population can be reached within $15 \mathrm{~min}$ by the (totally four) H-MMTs in the Netherlands (Fig. 1). After sunset and until midnight, the MMT is transported by a specially equipped vehicle. Table 1 shows the difference of the dispatch, assist and cancellation rate between the four MMT's in the Netherlands.

With the designation of ten Level-I trauma centres in the Netherlands in 1999, the prehospital and inhospital triage systems have become more important in providing a highquality trauma care. In 2008, an extra Level-I trauma centre was assigned, counting up to a total of 11 trauma centres in
Fig. 1 Mobile Medical Teams in the Netherlands

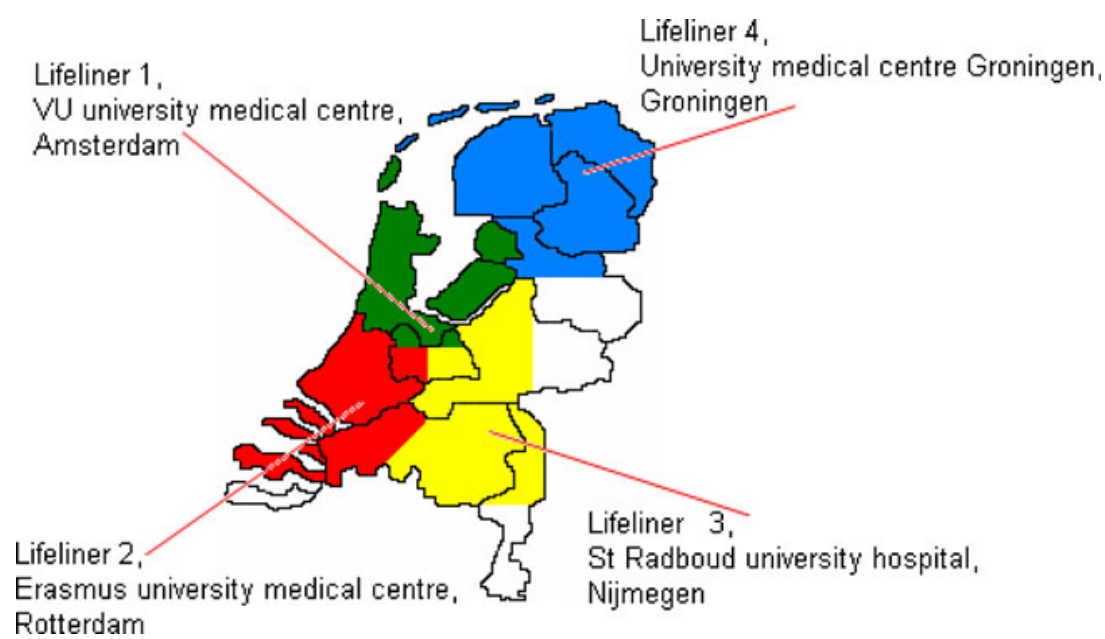


Table 1 MMT dispatches in the Netherlands in 2006

\begin{tabular}{|c|c|c|c|c|c|}
\hline MMT & Dispatches & Assists & Cancellations & Trauma & Non-trauma \\
\hline $\begin{array}{l}\text { Lifeliner } 1 \\
\text { VU University Medical Centre, Amsterdam }\end{array}$ & $\begin{array}{l}1,197 \\
(H=819, V=378)\end{array}$ & $\begin{array}{l}606 \\
(H=379, V=227)\end{array}$ & $\begin{array}{l}591(49.4 \%) \\
(H=440, V=151)\end{array}$ & $95 \%$ & $5 \%$ \\
\hline $\begin{array}{l}\text { Lifeliner } 2 \\
\quad \text { Erasmus University Medical Centre, Rotterdam }\end{array}$ & $\begin{array}{l}1,367 \\
(H=945, V=422)\end{array}$ & $\begin{array}{l}904 \\
(H=585, V=319)\end{array}$ & $\begin{array}{l}463(33.9 \%) \\
(H=360, V=103)\end{array}$ & $67.7 \%$ & $32.3 \%$ \\
\hline $\begin{array}{l}\text { Lifeliner } 3 \\
\text { St. Radboud University Hospital, Nijmegen }\end{array}$ & $\begin{array}{l}1,100 \\
(H=949, \mathrm{~V}=151)\end{array}$ & $\begin{array}{l}546 \\
(\mathrm{H}=498, \mathrm{~V}=48)\end{array}$ & $\begin{array}{l}554(50 \%) \\
(\mathrm{H}=451, \mathrm{~V}=103)\end{array}$ & $93 \%$ & $7 \%$ \\
\hline $\begin{array}{l}\text { Lifeliner } 4 \\
\quad \text { University Medical Centre Groningen, Groningen }\end{array}$ & $\begin{array}{l}1193 \\
(H=837, V=356)\end{array}$ & $\begin{array}{l}888 \\
(H=626, V=262)\end{array}$ & $\begin{array}{l}305(33.7 \%) \\
(\mathrm{H}=211, \mathrm{~V}=94)\end{array}$ & $75.8 \%$ & $24.2 \%$ \\
\hline
\end{tabular}

Annual reports Dutch HEMS Trauma centers 2006

$H$ mission by helicopter, $V$ mission by vehicle

the whole country. Prehospital triage systems have been developed and are constantly being renewed and adapted in order to stimulate an optimal distribution of trauma patients to the appropriate medical facilities, while inhospital triage systems have focused on the appropriate and prioritized use of these facilities [6].

The MMT handles a low activation threshold and is dispatched by the EMS dispatch centre at the same time as the ambulance crew (primary call). Alternatively, the ambulance crew can request a MMT at the scene of the accident for severely injured patients who are for example entrapped (secondary call). The criteria for the primary and secondary calls are listed in Fig. 2. It is possible for the ambulance crew, after arriving at the scene, to cancel the MMT dispatch in case they appear not to be necessary.

The MMT of the trauma centre North-West Netherlands, stationed at the VU Medical Center in Amsterdam, covers a territory of almost four million inhabitants with five EMS dispatch centres. Yearly, the MMT has been dispatched approximately 1200 times. In the second half of 2006, the amount of cancellations nearly reached $50 \%$.
The purpose of this study was to evaluate the cancellations of our MMT dispatches and to define the possible causes of this form of overtriage.

\section{Materials and methods}

All MMT dispatches in the TRNWN between July 2006 and December 2006 were included in this study. Dispatches from other regions were excluded because of handling other dispatch criteria, as well as patients with missing data.

Research data were extracted from the MMT database, the regional trauma registry of the VU Medical Center including the region hospitals, as well as the original ambulance forms.

Dispatches were divided in assists and cancellations. For each dispatch, we collected prehospital information related to reason for dispatch, vital signs (RR, HR and BP) and scores (Glasgow Coma Scale (GCS) and Revised Trauma Score (RTS)) of the victim at the scene and inhospital information related to the condition of the patient at the Emergency
Fig. 2 MMT dispatch criteria TRNWN

\begin{tabular}{|c|c|}
\hline Primary Launch Criteria & Secondary Launch Criteria \\
\hline $\begin{array}{l}\text { High Energy Trauma (Blunt) } \\
\text { (Bum }\end{array}$ & Threatened Airway \\
\hline Victim launched from vehicle/motorcycle & - Facial trauma \\
\hline Pedestrian hit by motor vehicle - speed $\geq 30 \mathrm{Km} / \mathrm{h}$ & - Corpus Alienum \\
\hline Fall from $\geq 5$ meter & - Edema (Quincke's or burn wound) \\
\hline Accidents involving: truck/subway/train/airplane/ship & - Stridor \\
\hline Multiple (seriously) injured victims (triage) & - Expected difficult intubation \\
\hline Prolonged extrication $\geq 15$ minutes & Threatened Breathing \\
\hline EMS traveling time $\geq 20$ minutes & $-\mathrm{O}_{2}$ saturation $\leq 96 \%$ with $\max \mathrm{O}_{2}$ administration \\
\hline Entrapment & - Multiple rib fractures, flail chest, lung contusion, \\
\hline Drowning / accidents involving submersion & Hemothorax, tension pneumothorax \\
\hline Severe hypothermia $\leq 32^{\circ} \mathrm{C}$ & - Breathing Frequency $\geq 30$ and $\leq 10$ per minute \\
\hline $\begin{array}{l}\text { Accidents involving: explosives/electricity/chemicals/ } \\
\text { radiation }\end{array}$ & $\begin{array}{l}\text { Threatened Circulation } \\
\quad-\mathrm{HR} \geq 120 \mathrm{p} / \mathrm{m}, \mathrm{SBP} \leq 90 \mathrm{mmHg} \text {, shock }\end{array}$ \\
\hline Pediatric resuscitation & Threatened consciousness \\
\hline Traumatic amputation of limbs above ankle or wrist & - Glascow Coma Scale $\leq 8$ or sudden drop of $>2$ \\
\hline Penetrating trauma (stab or gunshot) & - Pupil difference, epileptic state, severe CVA \\
\hline Possible trauma to airway, shock or coma. & - severely commotional/untreatable victim \\
\hline Burn victims $\geq 15 \%$ BSA or involvement of head/neck & Need for amputation on scene \\
\hline
\end{tabular}


Department (ED) vital signs and scores (GCS and RTS)), early surgery, admission at the ICU, length of stay in the hospital, mortality and the Injury Severity Score (ISS).

The above information was compared between assists and cancellations.

All dispatches were evaluated by using our regional MMT-dispatch criteria and the following mission appropriateness criteria, which are used as HEMS appropriateness criteria in the literature [7].

- $\quad$ ISS $\geq 16$ (if trauma).

- Death within $24 \mathrm{~h}$, unless no effort was made to resuscitate victim on-scene.

- Urgent surgical procedure immediately after ED admission.

- Admission to (Pediatric) Intensive Care Unit ((P)ICU).

Four groups were created based on the ISS anatomical body regions (injuries to head/thorax, or injuries to the remaining parts of the body) and type of dispatch (assist or cancellation).

The additional costs for the cancelled MMT dispatches were calculated based on the actual cost as found in the balance of payments of 2006 .

Statistical analysis was performed using the SPSS software package (SPSS 14.0 for Windows; SPSS, Chicago, IL, USA). Statistically significant was defined as $p<0.05$.

\section{Results}

During the second half of 2006 (July 2006 to December 2006), the MMT had 605 dispatches. Figure 3 shows a

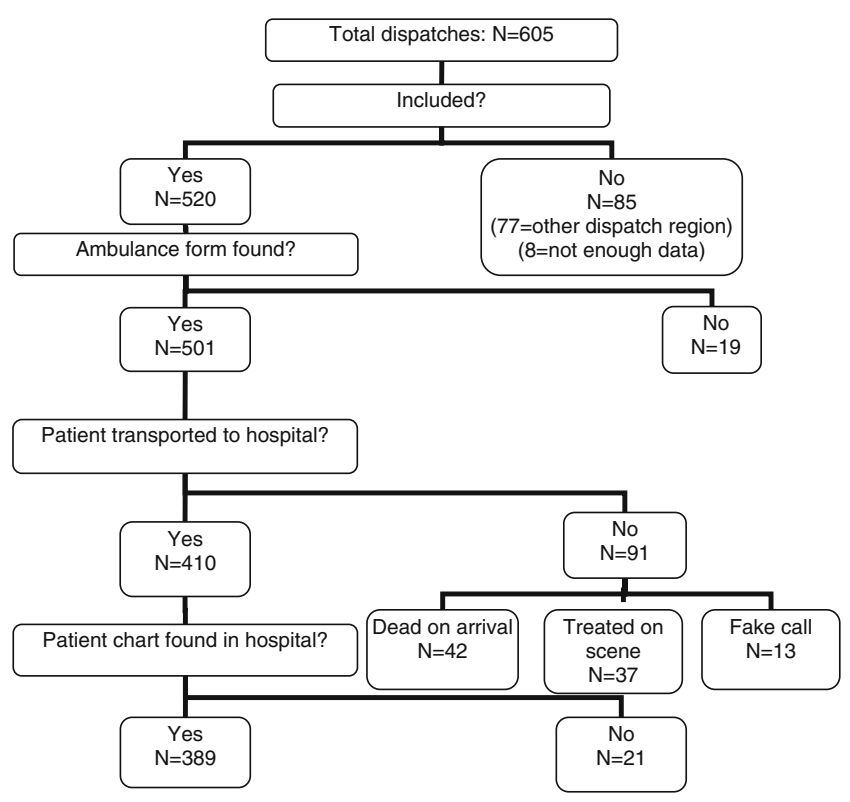

Fig. 3 Study population

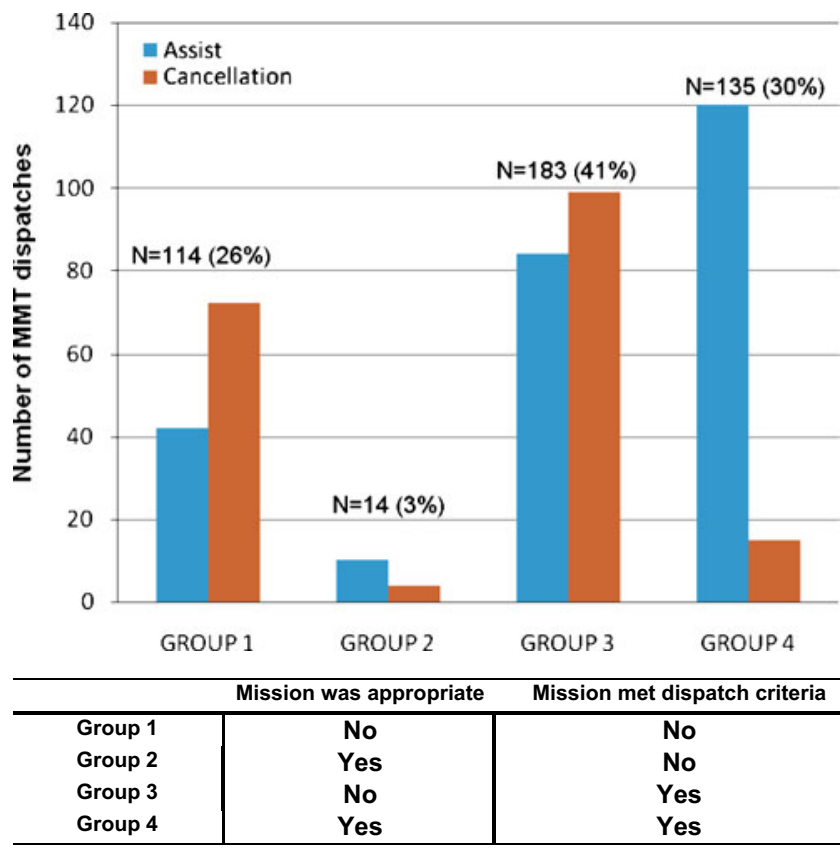

Fig. 4 Evaluation of the dispatches by using MMT-dispatch criteria and mission appropriateness criteria

summary of included and excluded cases. Of the 605 dispatches, 77 were excluded because these were requested by an EMS dispatch centre from another trauma region (different dispatch criteria). Eight were excluded as there was not enough information available to trace these back to the EMS dispatch centre.

From each mission, we included the most severely injured patient (in case there was more than one victim; Table 1). Of the 520 missions in our trauma region, 501 were matched to an original ambulance form. Of these, 41 patients died on-scene, 37 were treated on-scene without admission to an ED. In 13 cases, it concerned a fake call. Four hundred and ten patients were transported to 22 different emergency departments, of which 389 patient charts were retrieved and reviewed. Totally, 467 dispatches were included for this study (Fig. 4).

Table 2 lists the characteristics of the included dispatches and patients. The majority of the included missions were primary dispatches $(91.1 \%)$ and most of these were made by helicopter. In the remaining dispatches, the MMT was transported by vehicle.

Average age was 35.9 years, the majority of the patients were male $(65.3 \%)$. Four hundred and thirty patients were victims of trauma, sustaining injuries in most cases from blunt trauma (89.3\%). Thirteen patients were victims of penetrating trauma, and 44 patients sustained other type of trauma. The remaining 37 dispatches were of non-traumatic origin (17 cardiac, 17 neurological and three other).

All missions were categorized according to reason for dispatch/mechanism of injury (MOI) (Table 3). 
Table 2 Dispatch and patient characteristics of the 467 included cases

\begin{tabular}{lc}
\hline Total dispatches & 467 \\
\hline Cancellations & $203(43.5 \%)$ \\
Primary dispatches & $429(91.9 \%)$ \\
Helicopter dispatches & $320(68.5 \%)$ \\
Age (yr) (SD) & $35,9(21.7)$ \\
Male & $305(65.3 \%)$ \\
Trauma & $430(92.1 \%)$ \\
Blunt injuries & $417(89.3 \%)$ \\
\hline
\end{tabular}

After being dispatched $(n=467)$, the MMT was cancelled 203 times (43.5\%; Table 2).

The missions were divided in assists and cancellations. The characteristics of these missions were compared, and the results of which are shown in Table 4.

Not all ambulance forms were completely filled in, which resulted for 77 patients in a missing on-scene RTS $(19.8 \%)$ and for 71 patients in a missing on-scene GCS $(18.3 \%)$.

The ISS was calculated for 360 patients $(77.1 \%)$. For the remaining trauma patients, there was not enough information available about their injuries.

Statistically, significant differences between assists and cancellations were found for overall mortality, mean RTS, GCS and ISS, mean hospitalization (if necessary), length and amount of ICU admissions $(p<0.001)$. Overall mortality includes those who died after EMS and/or MMT arrived on-scene. Sixteen patients were dead on arrival. Age and sex did not significantly differ (Table 4).

All dispatches were evaluated by using the MMTdispatch criteria and mission appropriateness criteria (ISS $\geq 16$, death within $24 \mathrm{~h}$, urgent surgical procedure immediately after ED admission, admission to (Pediatric) Intensive Care Unit). Out of the 467 dispatches, 21 could

Table 3 Reason for dispatch/mechanism of injury (MOI) MMT of TRNWN VU University Medical Centre

\begin{tabular}{lc}
\hline Trauma & $430(92.1 \%)$ \\
Traffic accident & $237(50.7 \%)$ \\
Fall & $110(23.5 \%)$ \\
Drowning & $26(5.6 \%)$ \\
Assault & $15(3.3 \%)$ \\
Hit by heavy object & $15(3.3 \%)$ \\
Burns & $8(1.7 \%)$ \\
Hanging & $7(1.5 \%)$ \\
Other & $12(2.6 \%)$ \\
Non-trauma & $37(7.9 \%)$ \\
Cardiac & $17(3.6 \%)$ \\
Neurological & $17(3.6 \%)$ \\
Other & $3(0.6 \%)$ \\
\hline
\end{tabular}

not be evaluated as the available data were not enough for this purpose. We found that almost $26 \%$ of all dispatches were neither appropriate, nor met the dispatch criteria (group 1 in Fig. 4). Fourteen missions were appropriate, but did not meet the dispatch criteria (group 2 in Fig. 4). The remaining 318 dispatches had met the dispatch criteria (groups 3 and 4 in Fig. 4), of which 135 (30.3\%) were also appropriate (group 4 in Fig. 4).

Patient's injuries were compared for the assist and cancellation groups using the AIS anatomical regions from 360 trauma patients whose injuries were completely AIS coded (Fig. 5). The majority of injuries in the assist group are to head and thorax. This in contrast with the cancellation group, which shows a relative increase of injuries in the upper and lower extremities.

Four groups were created based on the ISS anatomical body regions and type of dispatch:

- Group 1 contains the MMT-assisted patients with injuries to the head and/or thorax

- Group 2 the MMT-cancelled patients with injuries to the head and/or thorax

- Group 3 the MMT-assisted patients with injuries to the remaining parts of the body and

- Group 4 the MMT-cancelled patients with injuries to the remaining parts of the body.

ISS means were compared for these groups with oneway ANOVA. A significant difference of $p<0.001$ was found between the means of all groups, except for groups 2 and 3. The mean ISS for group 1 was significantly higher than those for the other groups and was the only one to have a mean ISS above 16. Group 4 had the lowest mean ISS (Table 5).

The additional costs of all cancelled dispatches summed up to a total of $€ 34,448$. These costs consist of material and pilot costs for the helicopter and were calculated based on $€ 40$ per flight minute. For the MMT vehicle, which was a gift by the Dutch ministry of Internal Affairs, we assumed that the additional costs were negligible (the fuel costs were very low compared with the helicopter's, the personnel is in salaried employment; Table 6).

\section{Discussion}

It is difficult to define whether an MMT mission is medically appropriate or not [7]. The reason for this is that there has never been designed a prospective randomized study to assess the usefulness of physician-staffed prehospital trauma teams. Though, several retrospective studies indicated that the MMT in the Netherlands offers an increased chance of survival for severely injured patients 
Table 4 Analyses summary of all included patients $(n=467)$

$N S$ not statistically significant

${ }^{\text {a }} \chi 2$ test

${ }^{\mathrm{b}}$ Student's $t$ test

\begin{tabular}{llll}
\hline & Cancel & Assist & $P$ \\
\hline Male, $n$ (\% of total) & $118(68.2 \%)$ & $187(72.5 \%)$ & $\mathrm{NS}^{\mathrm{a}}$ \\
Mean age (year) & 34.7 & 36.7 & $\mathrm{NS}^{\mathrm{b}}$ \\
Overall mortality, n & 9 & 50 & $<0.001^{\mathrm{a}}$ \\
Mean revised trauma score & 11.45 & 9.41 & $<0.001^{\mathrm{b}}$ \\
Mean Glasgow Coma Scale & 14.06 & 10.61 & $<0.001^{\mathrm{b}}$ \\
Mean Injury Severity Score & 5.43 & 16.69 & $<0.001^{\mathrm{b}}$ \\
Mean length of admission (days) & 6.03 & 9.85 & $<0.05^{\mathrm{b}}$ \\
ICU Admissions, $n$ (and of total admissions) & $12(12.8 \%)$ & $71(42.3 \%)$ & $<0.001^{\mathrm{a}}$ \\
\hline
\end{tabular}

In our study, the on-scene patient's RTS was significantly lower in the MMT-assisted group then for the cancellation group. Previous studies have shown that a lowered RTS can recognize severe trauma victims, with a sensitivity ranging between $60 \%$ and $80 \%$. A similar study conducted in the Netherlands found lower results, ranging between $40 \%$ and $60 \%$ [17]. This difference is possibly seen because of the lower prevalence of trauma in our country due to traffic conditions, for example a high traffic load on the (high) way's due to demographic characteristics resulting in a relatively low average vehicle speed compared with the surrounding countries like Germany and Belgium [18, 19].

The mean prehospital GCS was also found to be lower in the MMT-assisted group. Prehospital lowered GCS has been shown to be a good predictor for inhospital trauma team activation, being indicative of possible serious trauma [20].

Limitation of triage to anatomic and physiologic criteria does not seem to be the solution, because this results in dangerous levels of undertriage. We can say that some degree of trauma mechanism and provider judgement needs to be incorporated [21]. Several retrospective studies have introduced new prehospital triage models to identify major
Fig. 5 Patient's injuries per AIS anatomical region

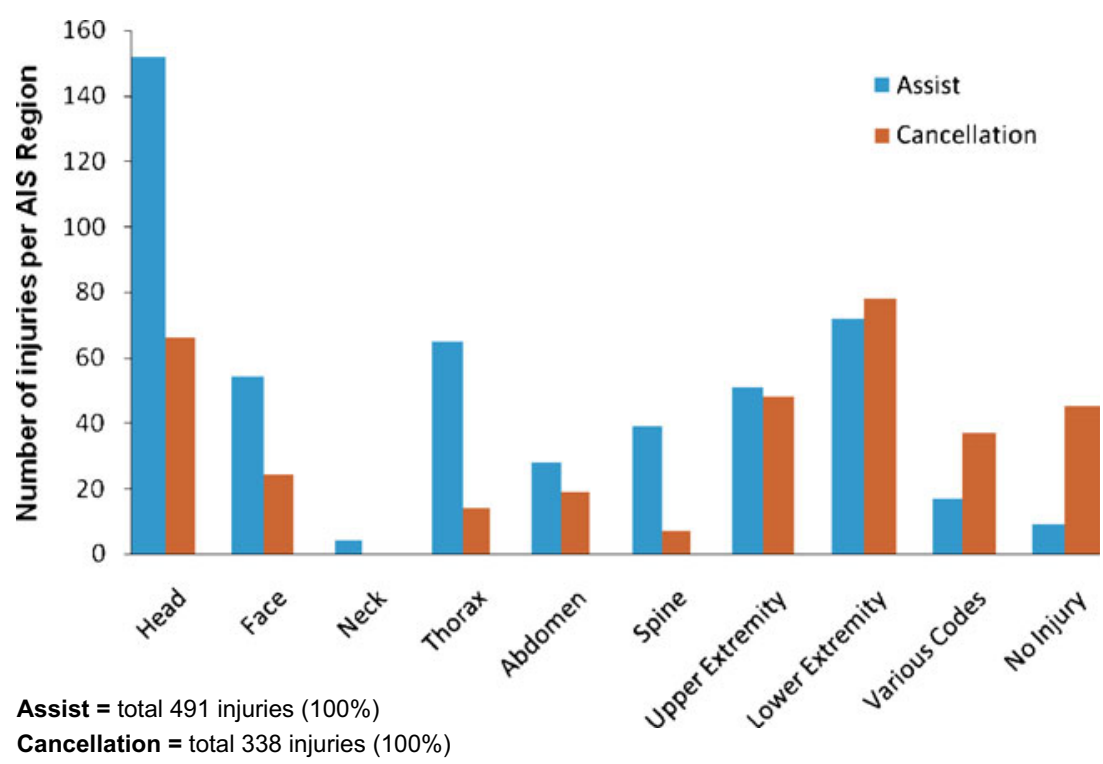


Table 5 ISS means of the four groups based on the ISS anatomical body regions and type of dispatch

\begin{tabular}{lc}
\hline Groups & Mean ISS (SD) \\
\hline Assist and injuries to the head and/or thorax & $20.69(15.71)$ \\
Cancellation and injuries to the head and/or thorax & $10.08(12.71)$ \\
Assist and injuries to the remaining parts of the body & $8.65(11.88)$ \\
Cancellation and injuries to the remaining parts of the body & $2.22(3.29)$ \\
\hline
\end{tabular}

trauma patients in the prehospital setting. However, these models still need to be validated in prospective studies [22].

Overtriage results in little impact to the patient, but it can result in significant strain on hospital and system wide resources and personnel. According to the American College of Surgeons - Committee on Trauma, an undertriage rate of $5-10 \%$ is considered unavoidable and is associated with an overtriage rate of $30-50 \%$. In this study, the MMT was cancelled in almost $50 \%$ of all dispatches. According to the above-mentioned, our cancellation rate is acceptable, but only if the undertriage rate is minimized. Figure 4 shows that the MMT was cancelled 19 times $(4.3 \%)$ while the mission was assessed to be appropriate (severely injured patient; cancellations of groups 2 and 4). These cases form the undertriaged group. According to the above-mentioned, we think that this combination of overand undertriage is acceptable in our trauma system. Of the 19 undertriaged patients, 11 were directly admitted to the ICU and two were directly brought to the operating room. Four of them died within $24 \mathrm{~h}$. Of these, two young patients died in the Emergency Department due to cardiac failure. One died at the scene of the accident and one in the ICU, both due to traumatic brain injury. In the last two cases, the MMT was cancelled because in one the patient was pronounced dead at the scene due to severe traumatic brain injury, in the other the patient needed emergency transportation to a hospital due to neurological symptoms. In the first two cases, the MMT was cancelled before even the ambulance arrived at the scene. The reason for cancellation was that it concerned in both cases a cardiac resuscitation instead of a trauma, which is not a primary dispatch criterion in our trauma region and in the Netherlands until today. Even thought the above-mentioned is true, we think that cardiac resuscitations, especially in young patients can be difficult and the presence of a specialized physician can be helpful.

An earlier study, conducted in the Netherlands, showed that the MMT can be considered cost-effective [23]. The calculat-

Table 6 Costs of MMT dispatches

Total MMT costs during study period

Mean cancelled dispatch flight duration

Total cancelled H-MMT dispatch costs ${ }^{\mathrm{a}}$

Mean cancelled H-MMT dispatch costs ${ }^{\mathrm{a}}$

${ }^{\mathrm{a}}$ Based on the actual cost as found in the balance of payments of 2006 ed additional costs of the cancelled dispatches summed up to a total of $€ 34,448$. Considering these costs amount to $2.2 \%$ of the total MMT costs during the study period ( $€ 1,537,747)$ [23], we think these costs are acceptable.

In our study, it was not possible to identify the group of patients who met the dispatch criteria and were severely injured, but for whom the MMT was not deployed at all (primary undertriage). The results of a study in another Dutch trauma region showed that emergency dispatchers only deployed the MMT in 14\% of all calls meeting the formal dispatch criteria. This means strict adherence to dispatch protocols can lead to an increase in the number of dispatches by a factor of seven [24].

Therefore, we suggest a study in our trauma region where all trauma emergency ambulance dispatches are included and the primary undertriaged patients are analyzed.

In 128 cases (groups 1 and 2 in Fig. 4), we saw that the mission did not meet the dispatch criteria. This may be a result of incomplete and unclear information given by a lay caller to the dispatch centre. Although in the literature we see cases where incomplete or unclear calls resulted in undertriage, we suppose that this can also cause overtriage [25]. Though, it is known that the use of criteria based dispatch systems increase the efficiency of emergency medical services. According to some studies in the USs, the use of these systems significantly decreased inappropriate advanced life support (ALS) dispatching, as defined by decreased rate of ALS cancellations. When dispatch protocols are used by personnel without ALS training, a rise of inappropriate scene responses and ALS cancellations is seen [26-28].

It was not possible to clearly define the reason of the cancelled, but appropriate missions in this retrospective study. We suppose that time plays a crucial role here. During daylight hours, the MMT is transported by helicopter, which is a fast way to reach the patient. After sunset and until midnight, the MMT is transported by a specially equipped vehicle. This may delay the arrival of the MMT on-scene, especially when the distance is long. In situations with unstable patients (threatened vital signs), the EMS personnel will have to choose between waiting on-scene for the MMT or transporting the patient as fast as possible to the nearest trauma centre and cancelling the MMT. The latter is a justifiable option in our opinion. After approval by the Ministry of Health, one of the Dutch H-MMT's (Lifeliner 3, Nijmegen) started a night pilot in 2006. This H-MMT is $24 \mathrm{~h}$ a day available and covers 
after sunset and especially after midnight almost the whole country. According to the results of this pilot, soon all four Dutch H-MMT's will be available day and night.

The MMT service has been designed to enable a trauma team to arrive as quickly as possible at the scene of injury. The team supplements but does not replace the EMS. Although it is proven that patient transport by helicopter offers a possible time benefit, only $2-15 \%$ of patients are transported by helicopter after on-scene treatment in the Netherlands. Due to geographic conditions, in the majority of the cases, within 20-30 $\mathrm{min}$, an appropriate level 1 trauma centre can be reached by ambulance after extrication of the injured patient at the accident scene.

In Europe, there is a great variation in organization of trauma care [29]. Many European countries have designated trauma centres and use mobile medical teams in the prehospital setting in order to improve trauma care [30]. Although the same idea is realized in different areas, substantial differences are seen in dispatch and cancellation frequencies. We think that this difference can be partially explained by the difference in dispatch types. Table 1 shows that the cancellation rate is lower for the MMT's with a higher non-trauma dispatch percentage. In a recent Dutch study, a comparison was made of the dispatch frequencies in different emergency dispatch regions by relating the dispatch of the MMT with the number of inhabitants. The deployment of the MMT proved to differ significantly between emergency dispatch centres. Dispatch centres coordinating MMT's conducted significantly more MMT calls with a lower cancellation rate [31].

Analysis of the German HEMS data of the ADAC (General German Automobile Association) of 33 German HEMS during the same (research) period showed an emergency dispatch rate of 17,823 , of which $14.3 \%$ were cancelled. Only $38.2 \%$ of all dispatches were of traumatic origin. This is not comparable with the results of our study, since in our study the dispatches were predominantly based on trauma indications (95\%). This could be caused by the difference between the Dutch and the German EMS systems. An ambulance crew in the Netherlands consists of two persons: an ambulance driver and an ambulance nurse. The ambulance nurse has being trained in $\mathrm{A}(\mathrm{T}) \mathrm{LS}$ and is allowed to perform many advanced medical procedures like endotracheal intubation and administration of analgesic medication. Therefore, the MMT in the Netherlands is predominantly needed in more difficult trauma related situations than in Germany.

\section{Limitations}

Retrospective, comparative observational studies are inherently less accurate than a properly setup prospective study.
We tried to minimize selection bias by performing a consecutive case review. Missing data however remains a clear obstacle in performing adequate research to trauma systems [32]. Also, several major obstacles to the development of quality EMS research exist. Funding is woefully inadequate and integrated information systems are needed to link data on patient care with information on outcome [33]. The properties of emergency medicine and trauma patients itself make it hard to apply the optimal scientific study design in this population. In trauma care, prospective (randomized) research in the prehospital is even more difficult. Although prehospital randomisation in trauma research is complex, it seems to be feasible. Therefore, we suggest a large prospective study were seriously injured patients are included, with the aim to trace and analyse the causes and reduce the rate of over- and undertriage.

\section{Conclusion}

In our trauma system, the MMT dispatches are involved with high rates of overtriage. After being dispatched, the MMT is cancelled in almost $50 \%$ of all cases. Although $4 \%$ of all patients were undertriaged, we think that this combination of over- and undertriage is acceptable. All cancellations were retrospectively justified. The additional costs of the cancelled missions were within an acceptable range.

In the Netherlands, the MMT-dispatch rate of traumatic origin is relatively high comparing to other European countries. There seems to be a relation between the increase of the non-traumatic dispatch rate and the decrease of the cancellation rate.

According to the results of this study, a reduction of overtriage seems to be possible, without increasing the undertriage rate to dangerous levels.

Further research is needed in order to assess the primary undertriage rate of our system and, if necessary, to refine the dispatch criteria.

Open Access This article is distributed under the terms of the Creative Commons Attribution Noncommercial License which permits any noncommercial use, distribution, and reproduction in any medium, provided the original author(s) and source are credited.

\section{References}

1. Utter GH, Maier RV, Rivara FP et al (2006) Inclusive trauma systems: do they improve triage or outcomes of the severely injured? J Trauma 60:529-535 discussion 535-537

2. Celso B, Tepas J, Langland-Orban B et al (2006) A systematic review and meta-analysis comparing outcome of severely injured 
patients treated in trauma centers following the establishment of trauma systems. J Trauma 60:371-378 discussion 378

3. MacKenzie EJ, Rivara FP, Jurkovich GJ et al (2006) A national evaluation of the effect of trauma-center care on mortality. N Engl J Med 354:366-378

4. Surgeons Committee on Trauma-American College of Surgeons (1998) Resources for optimal care of the injured patient. American College of Surgeons, Chicago

5. Henry MC, Alicandro JM, Hollander JE, Moldashel JG, Cassara G, Thode HC Jr (1996) Evaluation of American College of Surgeons trauma triage criteria in a suburban and rural setting. Am J Emerg Med 14:124-129

6. Fung Kon Jin PH, van Olffen TB, Goslings JC, Luitse JS, Ponsen KJ (2006) In-hospital downgrading of the trauma team: validation of the Academic Medical Center downgrading criteria. Injury 37 (1):33-40 Epub 2005 Oct 26

7. Petrie DA, Tallon JM, Crowell W, Cain E, Martell P, McManus D (2007) Medically appropriate use of helicopter EMS: the mission acceptance/triage process. Air Med J 26(1):50-54

8. Oppe S, De Charro FT (2001) The effect of medical care by a helicopter trauma team on the probability of survival and the quality of life of hospitalised victims. Accid Anal Prev 33(1):129-138

9. Frankema SP, Ringburg AN, Steyerberg EW, Edwards MJ, Schipper IB, van Vugt AB (2004) Beneficial effect of helicopter emergency medical services on survival of severely injured patients. Br J Surg 91(11):1520-1526

10. Hübner BL (1999) Evaluation of the immediate effects of preclinical treatment of severely injured trauma patients by Helicopter Trauma Team in the Netherlands. Ph.D. Thesis, Amsterdam

11. Hussain LM, Redmond AD (1994) Are pre-hospital deaths from accidental injury preventable? BMJ 308(6936):1077-1080

12. Papadopoulos IN, Bukis D, Karalas E, Katsaragakis S, Stergiopoulos S, Peros G, Androulakis G (1996) Preventable prehospital trauma deaths in a Hellenic urban health region: an audit of prehospital trauma care. J Trauma 41(5):864-869

13. Lehmann RK, Arthurs ZM, Cuadrado DG, Casey LE, Beekley AC, Martin MJ (2007) Trauma team activation: simplified criteria safely reduces overtriage. Am J Surg 193(5):630-634

14. Uleberg O, Vinjevoll OP, Eriksson U, Aadahl P, Skogvoll E (2007) Overtriage in trauma - what are the causes? Acta Anaesthesiol Scand 51(9):1178-1183

15. Boyle MJ (2007) Is mechanism of injury alone in the prehospital setting a predictor of major trauma - a review of the literature. J Trauma Manag Outcomes 1(1):4

16. Boyle MJ, Smith EC, Archer F (2008) Is mechanism of injury alone a useful predictor of major trauma? Injury 39(9):986-992

17. Roorda J, van Beeck EF, Stapert JW, ten Wolde W (1996) Evaluating performance of the Revised Trauma score as a triage instrument in the prehospital setting. Injury 27(3):163-167

18. Champion HR, Sacco WJ, Copes WS, Gann DS, Gennarelli TA, Flanagan ME (1989) A revision of the trauma score. J Trauma 29(5):623-629
19. Gilpin DA, Nelson PG (1991) Revised trauma score: a triage tool in the accident and emergency department. Injury 22(1):35-37

20. Norwood SH, McAuley CE, Berne JD, Vallina VL, Creath RG, McLarty J (2002) A prehospital glasgow coma scale score $<$ or $=$ 14 accurately predicts the need for full trauma team activation and patient hospitalization after motor vehicle collisions. J Trauma 53(3):503-507

21. Tiamfook-Morgan TO, Kociszewski C, Browne C, Barclay D, Wedel SK, Thomas SH (2008) Helicopter scene response: regional variation in compliance with air medical triage guidelines. Prehosp Emerg Care 12(4):443-450

22. Ocak G, Sturms LM, Hoogeveen JM, Le Cessie S, Jukema GN (2008) Prehospital identification of major trauma patients. Langenbecks Arch Surg 394:285-92

23. Ringburg AN, Polinder S, Meulman TJ, Steyerberg EW, van Lieshout EM, Patka P, van Beeck EF, Schipper IB (2009) Costeffectiveness and quality-of-life analysis of physician-staffed helicopter emergency medical services. Br J Surg 96(11):13651370

24. Ringburg AN, Frissen IN, Spanjersberg WR, Jel G, Frankema SP, Schipper IB (2005) Physician-staffed HEMS dispatch in the Netherlands: adequate deployment or minimal utilization? Air Med J 24(6):248-251

25. Karlsten R, Elowsson P (2004) Who calls for the ambulance: implications for decision support. A descriptive study from a Swedish dispatch centre. Eur J Emerg Med 11(3):125-129

26. Bailey ED, O'Connor RE, Ross RW (2000) The use of emergency medical dispatch protocols to reduce the number of inappropriate scene responses made by advanced life support personnel. Prehosp Emerg Care 4(2):186-189

27. Yeh EL, Cone DC (2000) Cancellation of responding ALS units by BLS providers: a national survey. Prehosp Emerg Care 4 (3):227-233

28. Culley LL, Henwood DK, Clark JJ, Eisenberg MS, Horton C (1994) Increasing the efficiency of emergency medical services by using criteria based dispatch. Ann Emerg Med 24(5):867-872

29. Sampalis JS, Denis R, Lavoie A, Fréchette P, Boukas S, Nikolis A, Benoit D, Fleiszer D, Brown R, Churchill-Smith M, Mulder D (1999) Trauma care regionalization: a process-outcome evaluation. J Trauma 46(4):565-579 discussion 579-81

30. Leppäniemi A (2005) Trauma systems in Europe. Curr Opin Crit Care 11(6):576-579

31. Lemson J, van Grunsven PM, Schipper IB, Valk JP, Christiaans HM, Gerritse EM, Scheffer GJ (2008) Helicopter-Mobile Medical Teams in The Netherlands: significant differences in deployment frequencies between different emergency room regions. Ned Tijdschr Geneeskd 152(19):1106-1112

32. Joseph L, Bélisle P, Tamim H, Sampalis JS (2004) Bias found in interpreting analyses with missing data for the prehospital index for trauma. J Clin Epidemiol 57(2):147-153

33. Salomone J (2004) Prehospital Care: generalized approaches to the traumatized patient. In: Moore EE, Feliciano DV, Mattox KL (eds) Trauma, 5th edn. McGraw-Hill, New York 